\title{
The Development of a Flood Protection System for Pad Transformers Using Pneumatic Pressure in Areas Prone to Floods
}

\author{
Gi-Hyun Kim* ${ }^{*}$ Jae-Yong Lee $\cdot$ Suk-Myong Bae
}

\begin{abstract}
The inundation of substation and ground power equipment breaks out every summer season in low-lying downtown areas and low-lying shores by torrential rain, typhoons and tsunamis. It has, in turn, caused replacement, social and economic costs for blackouts. For activity management regarding flood damage we produced a flood protection system which using the Pad transformer as a basic frame and is developed using pneumatic pressure. We tested safety concerns including insulation resistance and current leakage first for water tank flooding and, second, by an empirical test through supplying $22.9[\mathrm{kV}]$. We estimate that costs associated with flooding and power failure can be diminished by these advances toward creating a more reliable system.
\end{abstract}

Key Words : Flood Protection System, Pneumatic Pressure, Pad Transformer, Flood

\section{Introduction}

The inundation of substation and ground power equipment breaks out every summer season in low-lying downtown areas and low-lying shores by torrential rain, typhoons and tsunamis [1]. It has, in turn, caused replacement social and economic costs for blackouts. In addition, it appears that this kind of natural disaster will begin to take place more often due to domestic environmental changes [2].

* Main author : Assistance research engineer of KESCO

Tel : +82-31-580-3057, Fax : +82-31-580-3066

E-mail : ghkim7151@kesco.or.kr

Date of submit : 2010. 1. 12

First assessment : 2010. 1. 14

Completion of assessment : 2010. 1. 26
Therefore, it has been necessary to establish a fundamental flood protection plan in areas prone to floods, thus protecting electric power facilities such as transformers. That is why a system which can automatically supply and control pneumatic pressure by keeping the basic framework of the electric devices [3] has been developed.

According to the empirical test on the inundated products with a supply of $22.9[\mathrm{kV}]$, no problem was detected during the measurements of transformer temperature, energy consumption and insulation status. However, a further analysis needs to be conducted on the safety and reliability of the system for commercialization in flood areas and underground spaces. 


\section{Development of a Flood Protection System}

\subsection{Overview}

The flood protection system mentioned in this paper has been developed after selecting roadside pad transformers that were installed as a part of the metropolitan city underground project. In terms of structure, this system is safe using the upper enclosure which surrounds the electrical input booth in the front, the output terminal and the open bottom-type structure [3]. Even though it can vary depending on the type of the upper model of the pad transformer, the maximum height would only increase by approximately $10[\mathrm{~cm}]$. As shown in Fig. 1 below, the flood protection mechanism is operated in three stages. During the first and second stages, it is a top priority to control power transmission. At the third stage in which electric facilities are fully inundated, the mechanism protects them for more than 240 hours by controlling internal control terminals with compressed air and waterproof oil.

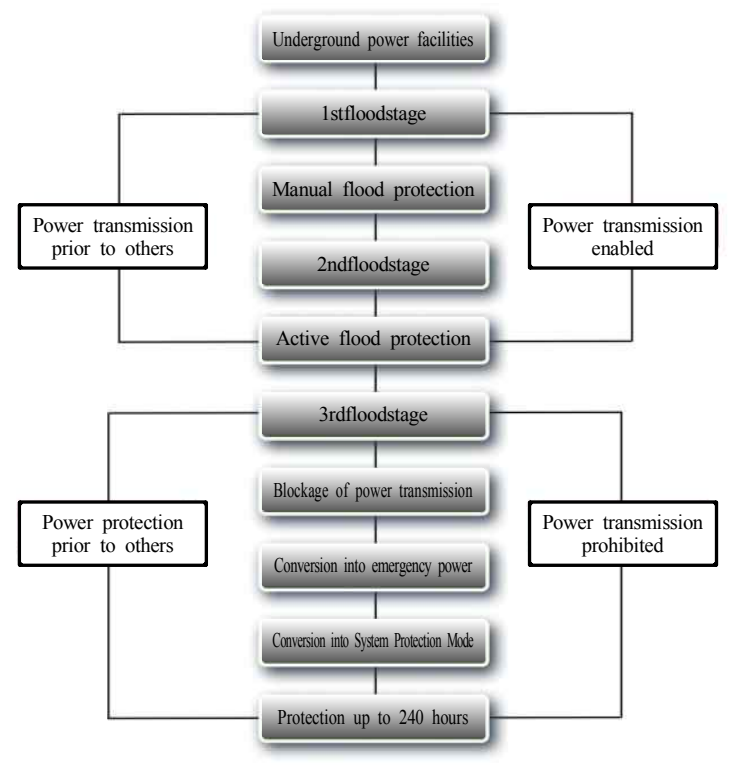

Fig. 1. Flood protection mechanism by flood stage
The active protection technology refers to a simple waterproof concept which prevents water from entering in the first flood stage. With the passage of time, the internal pressure starts to decline little by little and enters into the second flood stage. From this point, active flood protection takes place. As soon as a second stage water level is detected, the internal pressure adjusting device is activated to protect the system from flooding. In this stage, power is continuously supplied to the underground transformer. Unless the machine breaks down, the flood protection function stays active permanently. If a third stage flood is detected, it is very likely that underground transformer power would be interrupted. In this stage (complete flood mode), internal pressure is maintained under the system protection mode. The flood protection function is available until all air is fully consumed. In addition, an oil film formation system, which aims to prevent internal humidity from rising, will be available if necessary.

\subsection{Development of Internal Devices}

Once water starts to flow in, the water level is detected by the sensor. Then, the water level is immediately kept constant below the set level by the pneumatic pressure imposed by the pneumatic adjusting device.

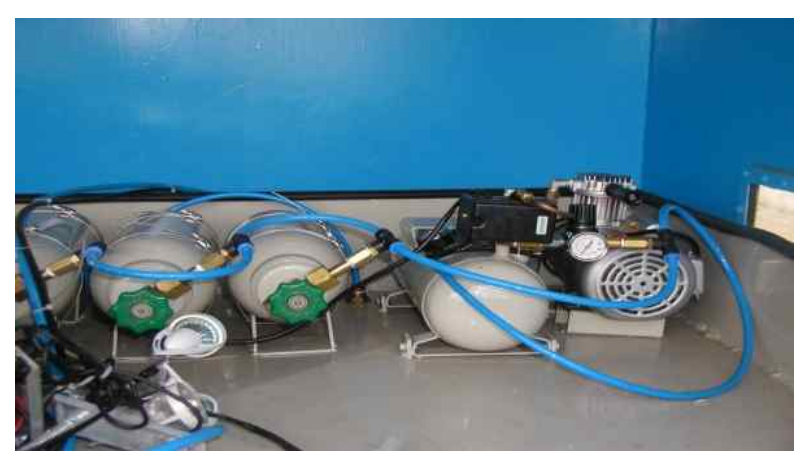

Fig. 2. Pressure generator 
During a flood, the internal pressure of the transformer is set depending on the flood level. As shown in Fig. 2 above, the air compression tank in the upper part can generate pneumatic pressure (up to level 7) [4]. If the water which flows inside the transformer is $15[\mathrm{~cm}]$ or deeper (sensor detection level), the pressure adjusting device is activated, which in turn adjusts the internal pressure of the transformer. In other words, the system is designed to prevent flood damage by blocking water inflow and the water supply in an emergency. During normal operation, it operates just like a general pad transformer in all aspects. No problem is detected in other parts, such as internal humidity or insulation resistance. According to the empirical test with $22.9[\mathrm{kV}]$, in addition, no problem has been observed in transformer temperature and insulation resistance when the flood protection system was activated. Fig. 3 below illustrates the outward diagram of the flood protection system.

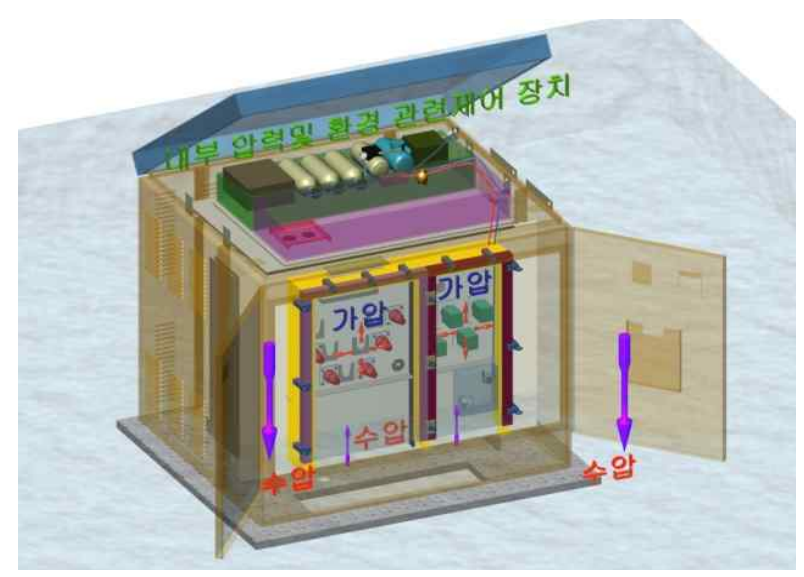

Fig. 3. Outward diagram of the flood protection system

A mechanism has been used which will allow the water level to decline if the internal pneumatic pressure increases through the open space at the bottom during a flood and vice versa. In addition, it prevents a certain level of water or pollutants from entering by setting the internal pressure equal to or larger than the pressure of the external water level through an auto adjustment of the air valve based on the internal water level.

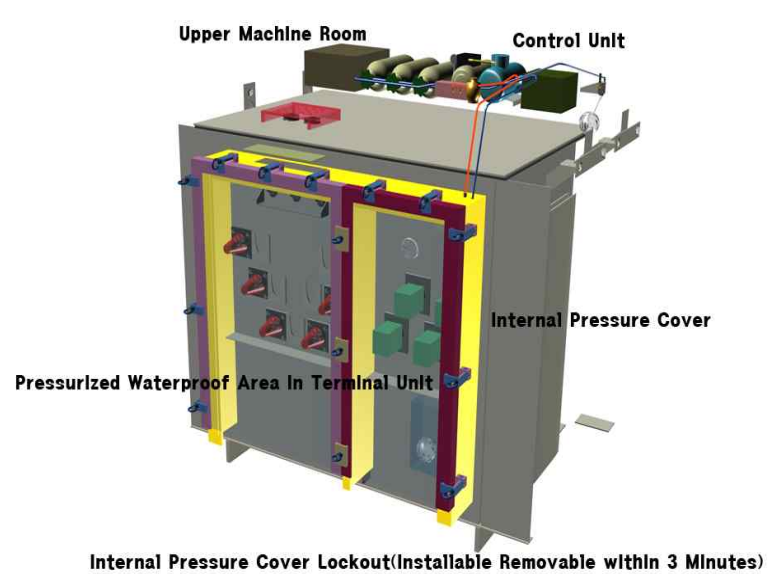

Fig. 4. Arrangement of the flood protection system

Fig. 4 shows the specific arrangement of the flood protection system. It consists of the upper enclosure which surrounds the input terminal $(22.9[\mathrm{kV}])$ and output terminal $(220[\mathrm{~V}] / 380[\mathrm{~V}])$ of the pad transformer, water level adjustor, pneumatic pressure tank, air supply valve and water level monitoring sensor. It appears that the flood protection pad transformer would minimize facility replacement and repair costs, which are caused by the inflow of pollutants such as mud during flooding, and economic loss caused by power failures [5].

\subsection{Flood Level Detection and Control Device}

During flooding, the inside of electric devices cannot be checked. Therefore, the system has been designed to make remote monitoring possible using a communication system so that related data can be transmitted even under special circumstances such as flooding. 


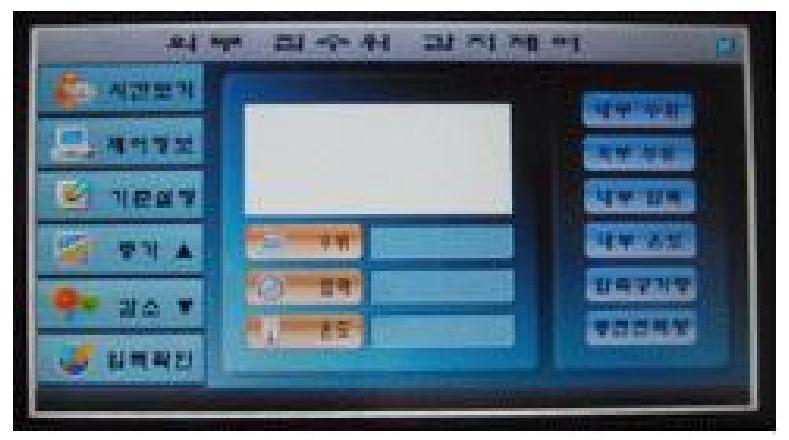

Fig. 5. Flood level detection and control device

As shown in Fig. 5, useful information such as the inner and outer water levels, internal pressure, transformer temperature, compressed air volume, battery level and time are properly set and displayed for users' convenience.

\section{Empirical Test on a Flood Protection Pad Transformer}

To test product reliability, a water tank (W 3[m] x H 3[m] x D 3[m]) was made as shown in Fig. 6 . Then, it was investigated to discover whether or not the flood protection system operated properly operated when water flooded; the pressure and insulation resistance of the pad transformer were also investigated. (a) Water tank

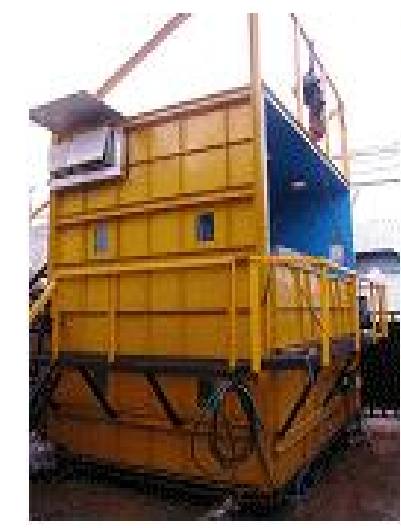

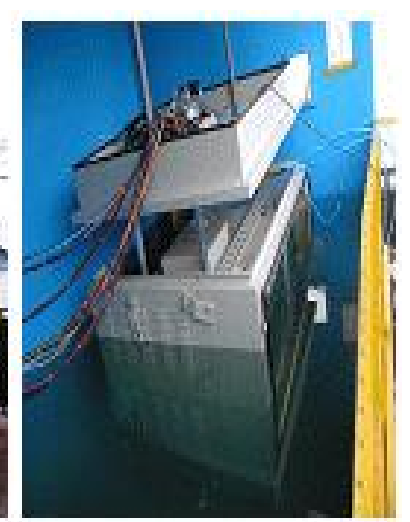

(b) Flood test
Fig. 6. Water tank and flood test
In addition, to check if a flood protection system is properly operated before and after a flood, as well as the safety and performance at $22.9[\mathrm{kV}]$ during a flood, an empirical test has been conducted at a $\mathrm{PAD}$ mounted transformer flood test site at the Korea Electric Power Research Institute in Gochang.

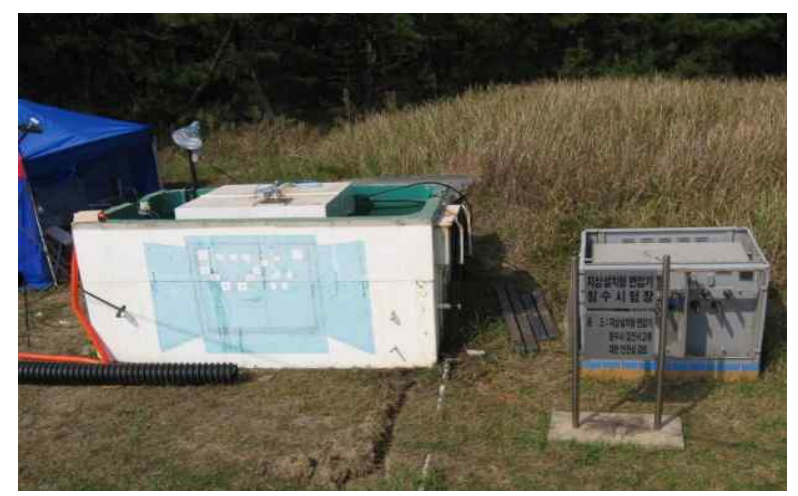

Fig. 7. Water tank in the empirical test site

A test has been conducted under three conditions: 1) no power available, 2) flood without power supply, and 3) flood with $22.9[\mathrm{kV}]$. As shown in Fig. 8 , performance of the flood protection system has been assessed in a water tank. In this test, the following was measured through each test: insulation resistance between the secondary side and tank, internal pressure, transformer insulating oil temperature, and pressurized energy consumption and leakage current on the secondary side of the transformer. Furthermore, it was investigated to see whether or not water flooded in up to the internal flood level under normal activation of the flood protection system. After installing a lamp load on the secondary side, it made it possible to check whether or not electric current flows into the pad transformer. To check the risk of electric shock in a flood, the tank's earth wire was connected at each phase on the secondary side of the transformer. In terms of insulation resistance, more than 2,000[M $[\mathrm{M}]$ was measured between each phase on the secondary 
side of the transformer and tank before a flood. As water flooded into the water tank, the internal flood protection system normally operated (no separate power necessary). As shown in Fig. 8 (left), the site was flooded up to $15[\mathrm{~cm}]$ only. Therefore, water did not flow inside the transformer.
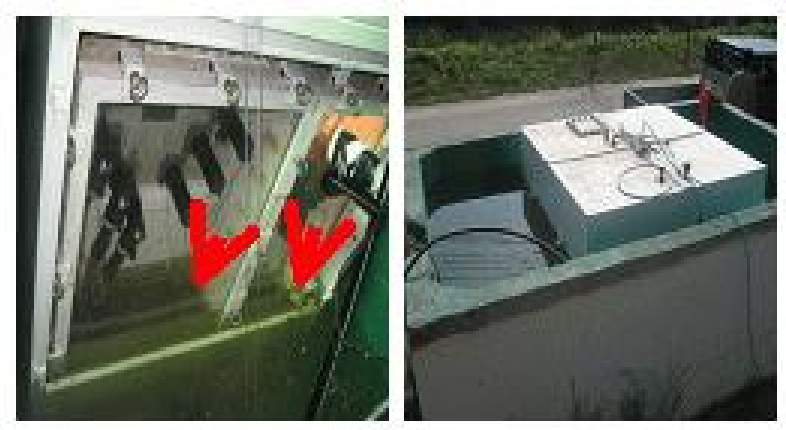

(a) Flood(inside vs. outside)

(b) Complete flood

Fig. 8. Test on transformer in complete flood

As shown in Fig. 8 (right) above, a test tank was completely flooded for 16 hours. In a complete flood, the insulation resistance between each phase on the secondary side of the transformer and tank started to drop from 2,000[MS] upon flooding. In 14 hours, 4[MQ] was maintained. In a flood lasting 16 hours, whether or not there was a problem in transformer temperature and insulation state was observed with an electric current of $22.9[\mathrm{kV}]$. However, no problem was detected. The electric current was maintained for 24 hours during the flood. Under this type of circumstance, the transformer insulating oil temperature stayed at $30\left[{ }^{\circ} \mathrm{C}\right]$. In terms of insulation conditions, $140[\mathrm{M} \Omega]$ was measured at the end of the final electric current. It has been confirmed that insulation resistance dramatically increased at the time of electric current compared to $4[\mathrm{M} \Omega]$ in flooding. In other words, it appears that insulation improved because humidity was partially reduced by the internal heat of the transformer caused by an electric current. According to the Electrical Equipment Technical Standards, the insulation resistance at $220[\mathrm{~V}] / 380[\mathrm{~V}]$ should be $0.2[\mathrm{MQ}]$ or greater. It has been confirmed that there would be no risk of electric shock which may occur during flooding [6]. Furthermore, according to the measurement on insulation resistance between each phase on the secondary side of the transformer and tank, when the water tank was empty with no electric current, 200[MQ] was measured. In other words, it has been confirmed that it is okay to use an electric current right after the water is pumped out after a flood.

\section{Conclusion}

In recent years, electrical facilities have often been flooded by torrential rain, typhoons and tsunamis in low-lying downtown areas and low-lying shores. As a result, social and economic damages have increased. To prevent these flood damages and actively respond to the flooding of electric equipment, therefore, a pneumatic pressure-based flood protection system has been developed. After setting the automatic flood protection system, which can generate pneumatic pressure up to level 7 , in the air compression tank and determining the internal pressure of the transformer depending on pressure fluctuations which are caused by a change in flood level, an empirical test was conducted. According to the test, no water flow was detected because of normal operation of the flood protection system. In addition, there was no problem in insulation resistance and transformer temperature with an electric current even during flooding. It appears that the result of this paper would increase the reliability and safety of the flood protection system and significantly decrease flood-related damages. 
This research has been carried out with the Electric Power Industry Basis Fund.

\section{References}

[1] Korea enviroment Institute reseach, "Sea Level Rise and its Possible Impact near the Korea due to Global Warming II", Report, 2002. 12.

[2] KPCO,"2006 Distribution Supply Equipment Power Failure Analytical and Preventive Countermeasure", Report 2007. 4

[3] KHPCO, "Korea Electric Power Corporation Standard Purchase Specifications (Pad Transformer), 2001. 6.

[4] Jae-Yong , Lee et 8, "The Development of Inundation Prevention Apparatus for Electric Power Equipment in Flood Area", Final Report, Yeungnam College of Science \& Technology, 2009. 2.

[5] Gi-Hyun, Kim et 3, "The Development of Flood Protection System for Pad Transformer using Pneumatic pressure", KIEI Vol.58P, No. 1, MAR., pp.90-94, 2009.

[6] Ministry of knowledge Economy, "The Korea Electric Power Industry Codes and Standards and , 2010. 1.

\section{Biography}

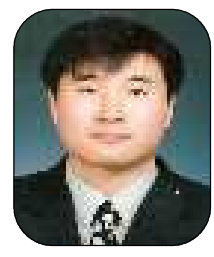

Gi-Hyun Kim

Born on May 1, 1971. Earned a Bachelor's Degree (1997), Master's Degree (Aug. 2000) and Ph.D. (Feb. 2008) in Electrical Engineering at Soongsil University. Acquired Licensed Professional Engineer Electric Safety in 2006. Assistance research engineer of KESCO (July 2003 - present)

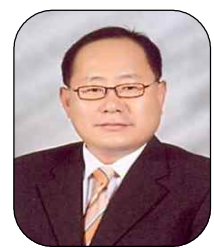

Jae-Yong Lee

Born on Oct. 10, 1966. Earned a Bachelor's Degree (Feb. 1991), Master's Degree (1993) and Ph.D. (1996) in Electrical Engineering at Kyungpook National University. Professor from Robotech Department of Yeungnam College of Science \& Technology(1995-present)

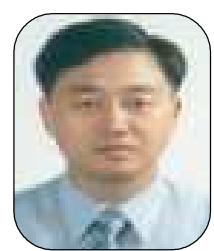

\section{Suk-Myong Bae}

Born on Oct. 22, 1956. Graduated from the Department of Electric Machines of Changwon Technical College in 1984. KESCO (1981-1997). Manager of Next-Generation R\&D Team of KESCO (1997 - present). 